\title{
Ildefonso Pereda Valdés y su Libro "Negros Esclavos y Negros Libres"
}

$\mathbf{L}$ A voz de Pereda Valdés está muy lejos de ser desconocida entre las que se han alzado para describir el estado pasado y presente del negro en la América del Sur. De modo que cuando el lector se da cuenta de la aparición de otro libro de este distinguido uruguayo, puede recibir la impresión de que está en presencia de otra polémica, sea en prosa o en verso. Tal impresión no sería del todo exacta, porque tenemos aquí no una obra netamente polémica ni netamente sociológica, antes bien, una combinación de crónica, examen del archivo nacional en lo referente a los negros en el Uruguay, corrección a veces animada de observaciones hechas por otros autores, $y$ por fin, alguno que otro pasaje apasionadamente defensor de la raza de color. Resulta un libro sumamente interesante que vale la pena examinar detenidamente, si bien se publicó en 1941 por orden especial del Présidente de la República Oriental.

¿Y quién es Ildefonso Pereda Valdés? A los que han seguido las actividades generales y muchas individuales del Instituto Internacional de Literatura Iberoamericana, no habrá necesidad de decirles que es catedrático de la Universidad de Montevideo, y autor de muchísimos libros y aún más artículos sueltos, panfletos, discursos, etc. Cabe apuntar, en forma de prólogo, que estas obras -que le han merecido muchos honores, como ser socio de varias Academias e Institutos - revelan una cultura vasta y sumamente humana.

No sabemos con exactitud qué edad tiene Pereda Valdés, pero todo rasgo de la pluma que esgrime tan acertadamente para discutir cuestiones de crítica literaria o para defender a la raza afroamericana, manifiesta que no ha perdido nada de la energía ni del gusto 
finísimo que lucía cuando dió a la estampa La casa iluminada, colección de poesías, en el año 1920. De veras aquella década de los 20 y tantos fué para el joven escritor su edad de oro poética: publicó en 1921 El libro de la colegiala; en 1926 La guitarra de los negros; en 1927 una antología, La moderna poesía urnguaya. Si bien esta obra es de sumo valor para el estudiante de la actual poesía uruguaya -realizándose en ella una fusión notable del catedrático de literatura y el poeta auténtico cuyos juicios merecen toda consideración-, quizá los lectores se detendrán más en La guitarra de los negros:

Hic sunt lacrimae terum et corda mortalia tangunt.

Pero no fué la del año 1927 su primera experiencia en el arte delicado y difícil de confeccionar antologías: en 1926 hizo publicar una Antología de la poesía negra americana. Siguen otros libros de versos: Raza negra, 1929; El romancero de Simón Bolívar, 1931, y Música y acero, 1933. En los mismos años le interesaba el ensayo como forma literaria muy capaz de responder a las necesidades imperiosas de quien debe comunicar no sólo sentimientos, sino también preceptos a un público muchas veces tardo en prestar su atención. Así es que escribe El arquero, 1924 ; después, El negro rioplatense, obra tal vez sin rival entre las de Pereda Valdés por lo serio y desafiador que es el texto de esta docena de ensayos; y Línea de color, 1938.

Pero este paladín de las letras no se dedica tan sólo a la causa de los humildes morenos; en el año 1937 publicó en Montevideo sú Cancionero de la guerra civil española, comprobante del hecho que ya torpe y tardíamente reconocemos aquí en los Estados Unidos: que los literatos sudamericanos se daban cuenta cabal de la derrota del mundo democrático en España, allá en los años en que los profesores de idealismo norteamericanos todavía se contaban entre los lotofagos.

Vemos pues que Ildefonso Pereda Valdés, cuando es "él", es un cincuenta por ciento poeta y otro cincuenta por ciento robusto defensor de buenas causas. El decir esto, es decir en resumidas palabras el argumento del presente estudio: en Negros esclavos $y$ negros libres se muestra Pereda Valdés no archivista frío e impasible, sino vivo y convencido; no historiador solamente de datos estériles, sino defensor sincero de la humanidad escamoteada. 
Esta feliz combinación de elementos imprescindibles para cualquier obra seria, fué saludada con entusiasmo por muchas autoridades sociológicas y etnológicas, entre los cuales citaré al doctor Fernando Ortiz, de Cuba, y al doctor Price Mars, de Haití, quien le escribió:

Felizmente, hay bellos libros como los suyos que compensan nuestra incapacidad provisoria de desplazamientos, por la abundancia, la precisión y la veracidad de sus informaciones.

Y la inspirada poetisa Gabriela Mistral le juzga así : "Me interesan profundamente los negros. Ud. los entiende maravillosamente."

Pero, ¿por qué citamos a los críticos cuando tenemos presente en sus escritos la sangre misma, por decirlo así, de Pereda Valdés? Abriendo al azar el precioso libro El negro rioplatense, encuentro en la página 20 esta referencia conmovedora a Sor Juana Inés de la Cruz:

Ella, que amaba al indio -y que lo cantó en sus versos-, ¿por qué no había de amat y cantar al negro, su hermano en el mismo dolor? . . Q Qué osadía, y qué coraje! Y la Inquisición la oye, y los mercedarios murmuran porque a ellos los alude, y los frailes tiesos y orondos toman nota de lo que la angelical criatura, tocada por la mano de la Poesía, dice con esa voz tan cálida, con ese fuego que une al cielo a la tierra, con esa voz tan cálida y tan queda.

¿ Para qué citar más? Lector benévolo, con estas palabras tan pocas pero tan sugestivas, ¿ no te hemos hecho penetrar en la noble alma de este poeta uruguayo?

Demos un vistazo a Negros esclavos y negros libres. Es libro de unas 172 páginas. Tiene catorce capítulos y un apéndice de copias de documentos históricos, citados en aquéllos, y de leyes y decretos referentes a los negros. Tratándose de una cosa humana, y por tanto ni simple ni rigurosamente ordenada, la obra no siempre se caracteriza ni por el orden ni por la sencillez. Sin embargo, en general sigue el orden histórico, y principia dando una breve relación de la llegada de los negros a las costas uruguayas. Era de suponer que este examen histórico trajera observaciones sobre el nefando tráfico de los negros del Congo y de Mozambique. De 1751 a 1810, entraron por el puerto de Montevideo unos 20,000 esclavos, "ya sea de tránsito o para aclimatarse en nuestra tierra". En la última fecha, la población de la ciudad se calcula en tnos 14,000. A veces, dice Pereda Valdés, la raza negra formaba la tercera parte de la pobla- 
ción de Montevideo. Cabe, pues, que el autor, y que nosotros mismos, nos preguntemos: primero, ¿qué tal era la sociedad que aceptaba este lastre como ferómeno natural e indiscutible?, y segundo, ¿cuáles eran las características del tráfico, semejantes, peores o mejores que las que acostumbramos achacar al sistema tal como se practicó en los Estados Unidos? Ni la primera ni la segunda cuestión ha escapado a la atención sagaz y moralizadora de Pereda Valdés, si bien es verdad que trata la segunda menos explícitamente de lo que yo hubiera deseado.

A decir verdad, difícil sería leer su capítulo interesantísimo "Costumbres de la colonia y síntesis de una sociedad esclavista" sin sacar la impresión de que se lee, en la obra actual, una crónica de la vida de los amos, y no de los esclavos. Es el retrato fiel e imparcial de un Montevideo donde había muy pocos libros, y donde la llegada de un viajero inglés o francés desconocido daba que hablar y conjeturar por horas sin fin. Otras diversiones eran las corridas, las riñas de gallos, algunas comedias, procesiones y bailes. Aquí se debe distinguir entre los lanceros y el minué de los aristócratas, y los candombes o antiguos bailes de los negros. Pereda Valdés muestra una singular pericia en su descripción de los bailes negros de hoy. Los acompaña con dibujos hechos por él mismo, en su libro El negro rioplatense. Pero es en su evocación de los candombes donde deja amplio curso a su veneración nostálgica de las cosas del pasado. También ilustra los bailes de esta clase con dibujos sencillos (p. 85). Del candombe dice lo siguiente:

Mấs tarde el candombe y la semba representan la evolución de las danzas primitivas. En la semba y el candombe ya no se aprecia tanto el retorcimiento frenético de la primitiva danza africana; la lascivia y el ftenesi han sido substituidas por la cadencia y el ritmo más lento. Porque el candombe no fué el "entrevero"' que nos pintó el doctor Figari (aquí tenemos una de las correcciones ya referidas. -H.). Según la versión que hemos recogido de un moreno casi centemario, Juan Viera, que desempeña el oficio de lustrabotas en la esquina de las calles Agraciada y Castro, el candombe se desarrollaba con la siguiente coreografía:

En la primera figura movimientos tiesos. Hombres y mujeres formaban dos filas: al lado una de otra. Las parejas iban formando eses. Entre tanto, el bastonero en medio de la sala impartía las órdenes. E1 Rey y la Reina permanecían sentados en el trono al frente del salón de baile; muy tiesos y orondos, saludaban a la concurrencia tomando muy a lo serio su papel de monarcas del candombe. E1 Rey 
se levantaba, llamando al "Interino" (una especie de Virrey). Acompañaban al Rey los príncipes (probablemente sus hijos) como e1 mameto de las Congadas, sólo que estos príncipes no mueren al golpe del "tacape".

El Rey y la Reina salian después a bailar. En medio de la sala - a los costados sonaban los tamboriles.

El bastonero cantaba:

$$
\begin{aligned}
& \text { Tingo enungambá } \\
& \text { saia do camino } \\
& \text { que yo quiero pasá. }
\end{aligned}
$$

Los candombes se realizaban en salones cerrados; empezaban de tarde y terminaban a media noche.

¿No hay en estas líneas, sobre todo en la referencia al negro lustrabotas, algo así como un eco dulce, tierno e inolvidable del pasado montevideano? Su habilidad en sintetizar se revela en la alusión a un pasaje del autor peruano Bustamante, que se halla en el libro intitulado Lazarillo de ciegos caminantes:

... Se comprenderá la diferencia entre la vida y el vestir del caballero limeño y el rioplatense: "En el sombrero traía (aquél) una toquilla de cinta de la China y para asegurarla una gran hebilla de oro, guarnecida de brillante... La capa era de paño azul finísimo de Carcasona, con bordados de oro... La chaquetilla que le cubría las rodillas era de terciopelo azul con más de dos mil ojales y otros tantos botones de oro... La chupa... tenía unos bolsillos que en cada uno cabrían holgadamente mil piezas..."

El mayor lujo de nuestros señotes esclavistas fué ostentar de cinco a diez esclavos a lo sumo. ¿Qué significa este lujillo ante el señor de la senzala que luce trescientos esclavos, o ante las religiosas de Córdoba que se hacen servir por igual número? (p. 74.)

Lo que a primera vista se nos antojó rencorcillo regional, se revela en una segunda lectura como castigo sutil, irónico, pero inexorable, de la sociedad esclavista.

Los turistas que -sin razón- han creído no descubrir en el Uruguay una clase media bien desarrollada, creerian ver apoyadas stus observaciones miopes en lo siguiente:

La clase media se fué desenvolviendo lentamente. El criollo por lo general fué poco afecto al comercio... Los pobres se dedicaban a faenadores, peones de estancia y cuando mucho calzaban de soldados... (p. 75.) 
Y sigue el catálogo de datos económicos, aparentemente algo aburrido, cuando de repente dice nuestro autor:

E1 pueblo no debió mejorar mucho en e1 vestir; ni su educación, ni su higiene y ni su salud preocupaban al Cabildo, que atendía con preferencia el interés de la clase alta y el cuidado de las calles principales como ocurte aún en la actualidad.

Por lo visto, a las viñetas del pasado de Montevideo suceden las del presente, y no enteramente satisfactorias!

Ahora, ¿ cuál es el criterio de Pereda Valdés con respecto a la esclavitud en el Uruguay?

En primer lugar, no condena el sistema en forma limitada, aplicable tan sólo a las condiciones uruguayas. En la página 31, dice:

La supuesta inferioridad de ciertas razas, como la negra, pudo ser otro motivo para justificar durante mucho tiempo una institución tan odiosa como la esclavitud. Hoy en día, con los mismos principios de inferioridades raciales, se somete a los judíos a una opresión degradante. La esclavitud en la antigüedad pagana conoció otro origen: la guerra, y en la época moderna se agregó otro motivo: la codicia de los traficantes que explotaron al esclavo negro como una mercancía con la tolerancia de naciones cristianas y civilizadas como Inglaterra, Francia, España y Portugal, que consintieron y estimularon el tráfico con sus colonias.

4 " Naciones cristianas civilizadas!" En cuatro palabras se condensa toda la condenación majestuosa de este espíritu justo y clarividente.

Sigue la exposición histórica del tráfico en el Uruguay, y siguen a intervalos regulares las expresiones de ira, que no son, sin embargo, explosiones, sino a menudo finas y discretas sugestiones de ironía: "Fernando el Católico tuvo sus escrúpulos" (p. 34) ; "tardío arrepentimiento fué el de Las Casas ante el sufrimiento de los esclavos!" (p. 34) ; "las primeras piezas de ébano" llama a los esclavos (p. 34); v dice que "el tráfico se convierte en un pingüe negocio". En la página 54 leemos: "A los que ocultaban a los negros huidos, si eran negros o mulatos se les castigaba con la pena de muerte; si españoles, el castigo era de destierro. Ejemplo de discriminación de razas que hace la pena siempre más severa para el negro, aun tratándose de individuos de la misma raza."

A este capítulo sobre discriminación racial le sigue otro sobre las leyes y códigos negros. Pero, $i$ mucho ojo! Este autor humanitario 
nunca pierde los estribos. Ahí donde se muestra más severo es precisamente donde se destaca mejor su sereno criterio de la justicia más absoluta. $\mathrm{Y}$ las páginas 56 y 57 son dignas de grabarse en letras de oro, siempre visibles para los que quisieran humillar a España con "leyendas", o como quiera que se les llame. Termina este bello pasaje así :

No sabemos a ciencia cierta si estos principios (v. gr., humanitarios) se cumplieron en la práctica, o si quedaron en el papel como meras declaraciones platónicas. Las leyes se forjaban en España y se cumplian en las Indias, a muchas millas de distancia, y a menudo, en la misma travesia se deformaban al caer en manos de los ejecutores. Pero el hecho es que existieron tales necesidades y frente a una legislación bárbara y rigorista, surgió el principio de la equidad que suaviza la dura ley en la voluntad de los príncipes a quienes el espíritu cristiano que alentaba en sus confesores o consejeros, y a veces el mismo humanitarismo reformista, inspiró lenitivos a los males de una legislación medioeval y a una conquista violenta.

En este examen general, de poco servirian las condenaciones, ni de mucho más la justicia impasible, si no se les agregasen algunos atributos positivos. No olvidemos que el tema general de Pereda Valdés son "negros esclavos - y negros libres". El negro ha hecho su contribución a la gloria uruguaya, como lo demuestra nuestro autor en dos capítulos muy interesantes: "Resabios esclavistas y persistencia del espíritu colonial en los primeros tiempos de la independencia" y "Aporte del negro a nuestra formación nacional". Indudablemente, dice Pereda Valdés, el negro influyó en las costumbres de la época colonial; "como soldado, el aporte del negro fué más importante". Veamos qué ayuda valiosa prestó el humilde pardo Luna, asistente del general uruguayo Rivera:

El general Rivera se encontraba en 1828 en Santa Fe; Rivadavia había decretado su prisión; falto de recursos y en situación angustiosa ... su único compañero era su asistente el pardo Luna. Cierta noche cenaba Rivera con él y, perplejo, se preguntaba qué debía hacer. Luna le sugiere la idea de presentarse personalmente a Rivadavia para destruir con su presencia y su sinceridad acendrada, la urdimbre de intrigas que le habían tejido sus enemigos. Acepta la idea Rivera... pero surge una dificultad casi insalvable para realizar su proyecto de viaje a Buenos Aires: el dinero... Sus amigos se hallaban lejos y el proscripto a la fuerza se enredaba en la más delicada situación. 
Luna desaparece por unos días y retorna al cabo con una fuerte suma de dinero, ganada honradamente, según se lo había manifestado a su protector. Luego vuelve a desaparecer sin que se sepa nada de él. Indaga Rivera, y al fin, llega a saber, que su asistente se había vendido como esclavo para obtener la suma que entregara generosamente al vencedor del Rincón. Rivera acudió a casa del comprador de Luna, manifestándole a éste la imposibilidad en que se encontraba de pagar el rescate. Le expuso el caso, y se atribuyen al no menos generoso amo, estas palabras: "Me apresuro a devolveros a vuestro hombre, sin compensación alguna, pues sería para mí un cargo de conciencia conservar como esclavo al que por la nobleza de sus sentimientos ha nacido para ser libre y así asocio mi nombre al vuestro, con lo cual os complazco y me honro." (pp. 115-116.)

En los dos últimos capítulos leemos de la abolición de la esclavitud. Esta se debe a las circunstancias, según Pereda Valdés, más que a las campañas de los abolicionistas:

La abolición se impuso sin derramamiento de sangre y sin mayor oposición, a medida que las circunstancias la indicaban. Tuvo un proceso lento - desde el año de 1815 a 1851 - y por lo mismo gradual y tranquilo. Empezó con el reclutamiento de esclavos para engancharlos en el ejército y terminó con el licenciamiento de los mismos; las leyes (de las que Pereda Valdés nos hace el comentario de que en 1839 y otra vez en 1842 eran letra muerta; seguían vendiéndose negros, si bien con cierto disimulo.-H.) no fueron más que la decoración exterior de ese proceso determinado por la necesidad política y la influencia de Inglaterra. (p. 133.)

Hay que confesar que el vigoroso poeta de La guitarra de los negros, el ensayista estimulador de El negro rioplatense, parece carecer de bríos en este final. ¿ Por qué? ¿ No es porque se ha esforzado por escribir, no una polémica, de que naturalmente no había necesidad, tampoco una historia, sino una especie de charla calma y apacible, en la que estuviesen bien refrenadas las emociones? $Y$ ¿qué eștilo convendría más al poeta de libros tan fundamentalmente distintos como el Cancionero de la guerra civil española, de un lado, y La guitarra de los negros y Raza negra, del otro? Repetimos: Pereda Valdés es muy capaz de ser cruzado y de luchar por una causa santa; pero su personalidad no es nunca simple: demuestra mucha cerebración para entregarse enteramente al juego de las emociones, por muy estético que sea, y nunca este batallador olvida que también es crítico literario, investigador sociológico, y a mayor abundamiento, catedrático de la Universidad de Montevideo. 
Este equilibrio, regularmente sostenido en sus procesos mentales, es la mejor garantía - si no me equivoco soberanamente- de que sus escritos perdurarán, mientras las obras más acaloradas de ciertos contemporáneos siguen cayendo en un olvido cada vez más completo.

Explica también por qué nos ocupamos, con mayor preferencia tal vez, de las secciones de Negros esclavos y negros libres que tratan del folklore negro. Sabíamos ya que El negro rioplatense es sencillamente un arca de tesoros folklóricos tocantes al aporte del negro a las supersticiones, así como al vocabulario oriental. Ya en los años posteriores a 1937 - año de la publicación de El negro rioplatense y también año en que tuve el placer de conocer y tratar en relaciones de amistad literaria a Pereda Valdés-, sabíamos que cundía su fama de intérprete de la raza negra por todo país latinoamericano. Fué, pues, con fruición muy íntima como leí en el libro presente los capítulos intitulados "Costumbres de los negros orientales" y "Folklore". Constituyen un progreso de refinamiento, un grado más alto de comprensión, un perfeccionamiento, si cabe, en el campo en que se especializa nuestro autor. Limitaciones bien comprensibles no me permiten comentar aquí las riquezas que encierran tales capítulos. Unicamente transcribo, como final adecuado de esta crítica, la canción de un esclavo negro (p. 101):

\footnotetext{
Yo me llamo Francisco Moreno

que me vengo de confesá

con el cura de la parroquia

que me entiende la enfemelá.

Curumbé, Curumbé, Curumbé,

Curumbé, Curumbé, Curumbé,

que mi amo me quiele vendé

porque dice que yo no sabo

ni flegá ni cusiñá,

Curumbé, Curumbé, Curumbé.

Apuntuté señol esclibano,

apuntuté con la pluma en la mano

los vestidos de mi mujé

que están colgados en la paré,

Curumbé, Curumbé, Curumbé.
}

\author{
Henry A. Holmes, \\ College of the City \\ of New York.
}


